\title{
Comparison of coagulase, deoxyribonuclease (DNase), and heat-stable nuclease tests for identification of Staphylococcus aureus
}

\author{
ROSALIE E. MENZIES \\ From the Microbiology Department, Green Lane Hospital, Auckland, New Zealand
}

SUMMARY One thousand and thirty-five clinical isolates of the genus staphylococcus were used to compare the coagulase test with the deoxyribonuclease (DNase) and heat-stable nuclease tests as methods for identifying Staphylococcus aureus. Conflicting results were obtained with 65 isolates when the coagulase test was compared with the DNase test but with only one isolate when the coagulase test was compared with the heat-stable nuclease test. The heat-stable nuclease test produced reliable results after four hours' incubation and was considered a satisfactory substitute for the coagulase test in the clinical laboratory.

Most clinical laboratories identify Staphylococcus aureus by the coagulase test. In 1958 Di Salvo reported that a test for deoxyribonuclease (DNase) correlated perfectly with the coagulase test and since then some laboratories have used the DNase test routinely for identifying Staph. aureus. However, Zierdt and Golde (1970) demonstrated that some Staph. epidermidis strains produce small quantities of DNase and could be misidentified as Staph. aureus by this test. Lachica et al. $(1971 \mathrm{a}, \mathrm{b})$ demonstrated that heat-stable nuclease production was specific for Staph. aureus and described a test suitable for use in a clinical laboratory. Their method presented difficulties with manipulation and desiccation of reactants. Modifications were made in the present investigation to eliminate these problems.

The purpose of this study was to ascertain which of the three tests could be used to identify clinical isolates of Staph. aureus with the greatest simplicity, speed, and accuracy.

\section{Material and methods}

One thousand and thirty-five bacterial isolates from clinical specimens were identified as genus staphylococcus by colonial morphology, Gram stain, catalase production, and growth in $10 \%$ salt broth at $37^{\circ} \mathrm{C}$.

Received for publication 4 January 1977
Coagulase production was detected either by the method of the Subcommittee on Taxonomy of Staphylococci and Micrococci (1965) using human plasma or the method using ethylenediaminetetraacetic acid (EDTA) treated coagulase plasma (Difco) according to the maker's instructions. Formation of a clot after 1, 2, 4 or 24 hours was regarded as positive.

Heat-stable nuclease production was tested by the method of Lachica et al. (1971a) using a microcapillary tube. The method is shown diagrammatically in Figure 1. The microcapillary tube was used to remove a plug of agar containing a single colony from a culture on sheep blood agar. The agar plug was moved to the centre of the tube with a sterile straight wire and the ends of the tube were sealed in a bunsen flame. Each tube was labelled with autoclave tape and submerged in a boiling water-bath for 15 minutes. On removal, the ends of the tube were cut open and the solidified agar plug was ejected onto toluidine blue $\mathrm{O}$ deoxyribonucleic acid (DNA) agar. The test agar was incubated at $37^{\circ} \mathrm{C}$ and examined after four hours. Positive tests showed bright pink zones about $1 \mathrm{~cm}$ in diameter which usually appeared within one hour (Fig. 2).

DNase production was tested on DNase test agar (BBL) following the procedure described by the manufacturer. During the investigation quality control tests indicated that one batch of DNase test agar (BBL) was deficient in DNA and $0.1 \%$ DNA (BDH) was added to this medium to enhance detection of DNase. 


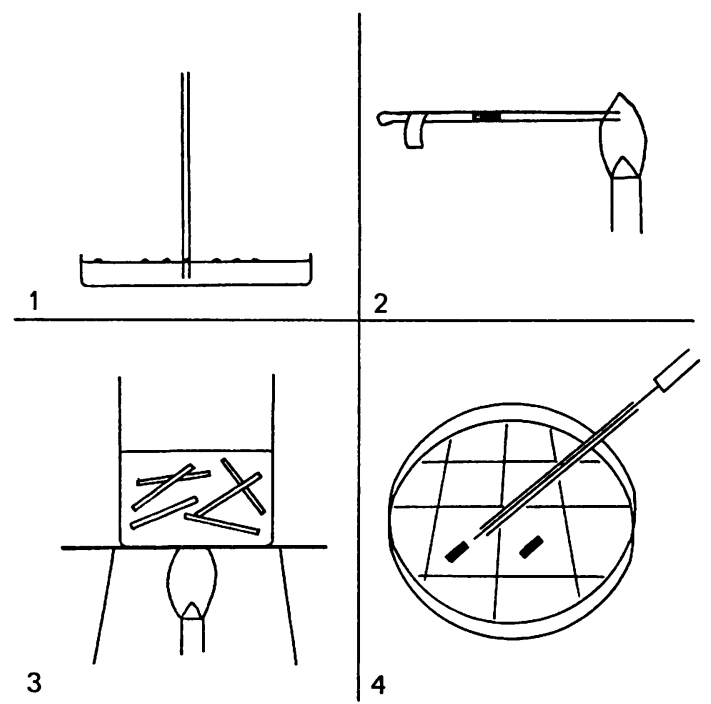

Fig. 1 The heat-stable nuclease test: 1 microcapillary tube removing a colony and underlying agar; 2 sealing the microcapillary tube; 3 boiling water-bath for 15 minutes; 4 inoculating toluidine blue 0 DNA test agar.

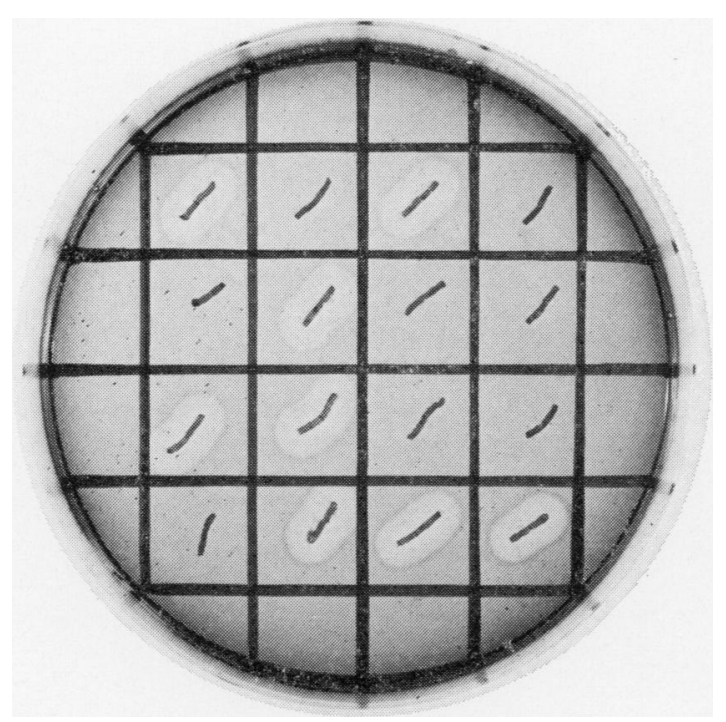

Fig. 2 Toluidine blue 0 DNA agar plate showing positive and negative heat-stable nuclease tests after incubation for one hour at $37^{\circ} \mathrm{C}$.

\section{Results}

When the coagulase and heat-stable nuclease tests were compared there was a conflicting result for only one of the 1035 isolates (see Table).
Table Results of coagulase test compared with results of deoxyribonuclease (DNase) and heat-stable nuclease tests for 1035 isolates of the genus staphylococcus

\begin{tabular}{llll}
\hline Test & & $\begin{array}{l}\text { Coagulase- } \\
\text { positive } \\
(n=728)\end{array}$ & $\begin{array}{l}\text { Coagulase- } \\
\text { negative } \\
(n=307)\end{array}$ \\
\hline DNase & Positive & 719 & 56 \\
Heat-stable nuclease & Negative & 9 & 251 \\
& Positive & 728 & 1 \\
& Negative & 0 & 306 \\
\hline
\end{tabular}

However, when the coagulase and DNase tests were compared, there were conflicting results for 65 of the isolates. Nine $(1 \%)$ coagulase-positive isolates were DNase-negative and $56(18 \%$ )coagulasenegative isolates were DNase-positive. The one coagulase-negative isolate that was heat-stable nuclease-positive was DNase-positive.

Tests for DNase production on the defective DNase agar (BBL) gave 121 negative results. When these tests were repeated on normal DNase agar (BBL) and defective DNase agar (BBL) to which $0 \cdot 1 \%$ DNA had been added, 91 negative and 30 positive results were obtained. The 91 DNasenegative and three of the DNase-positive isolates were coagulase-negative. The remaining 27 DNasepositive isolates were coagulase-positive.

\section{Discussion}

Rapid identification of Staph. aureus has not always been possible because some strains that give a negative slide coagulase test may take 24 hours to produce a result by the tube coagulase method. This study demonstrated that the heat-stable nuclease test gives a satisfactory result after only four hours' incubation.

Both the coagulase and heat-stable nuclease tests were simple and inexpensive to perform. The heatstable nuclease test required more preparation than the coagulase test but produced fewer quality control problems and results that were easier to read. Staph. aureus is the only bacterial species known to produce heat-stable nuclease, and false positive reactions due to other bacterial species have not been described (Rayman et al., 1975). However, diffusion of heat-stable nuclease through the agar from an adjoining Staph. aureus colony could result in a false positive reaction. The coagulase test can also be subject to false positive results due to either citrate utilisation or coagulase-like activity. This has been demonstrated in some strains of Pseudomonas aeruginosa, Serratia marcescens and Streptococcus faecalis (Baird-Parker, 1965).

The DNase test did not correlate closely with 
either the coagulase test or the heat-stable nuclease test.

The observation of Zierdt and Golde (1970) that some coagulase-negative staphylococci produce sufficient DNase to give positive DNase results was confirmed in this study when 56 of the isolates tested fell into this category.

Coagulase production has been established as the definitive characteristic of Staph. aureus for many years. The latest edition of Bergey's Manual of Determinative Bacteriology (Buchanan and Gibbons, 1974) now includes heat-stable nuclease (heatresistant endonuclease) production as another important characteristic. The results of this investigation confirmed the usefulness of the heat-stable nuclease test as a means of identifying Staph. aureus in a clinical laboratory.

I thank Dr D. MacCulloch and Mr B. Cornere for their interest and assistance.

\section{References}

Baird-Parker, A. C. (1965). The classification of staphylococci and micrococci from world-wide sources.
Journal of General Microbiology, 38, 363-387.

Buchanan, R. E. and Gibbons, N. E. (eds.) (1974). Bergey's Manual of Determinative Bacteriology, 8th edition. Williams and Wilkins, Baltimore.

Di Salvo, J. W. (1958). Desoxyribonuclease and coagulase activity of micrococci. Medical Technicians Bulletin, 9, 191-196.

Lachica, R. V. F., Genigeorgis, C., and Hoeprich, P. D. (1971a). Metachromatic agar-diffusion methods for detecting staphylococcal nuclease activity. Applied Microbiology, 21, 585-587.

Lachica, R. V. F., Hoeprich, P. D., and Genigeorgis, C. (1971b). Nuclease production and lysostaphin susceptibility of Staphylococcus aureus and other catalasepositive cocci. Applied Microbiology, 21, 823-826.

Rayman, M. K., Park, C. E., Philpott, J., and Todd, E. C. D. (1975). Reassessment of the coagulase and thermostable nuclease tests as means of identifying Staphylococcus aureus. Applied Microbiology, 29, 451-454.

Subcommittee on Taxonomy of Staphylococci ard Micrococci (1965). Recommendations. International Bulletin of Bacteriological Nomenclature and Taxonomy, 15, 109-110.

Zierdt, C. D. and Golde, D. W. (1970). Deoxyribonuclease-positive Staphylococcus epidermidis strains. Applied Microbiology, 20, 54-57. 